Institute of $\mathbf{F}_{\text {ood and }} \mathbf{A}$ gricultural $\mathbf{S}_{\text {ciences }}$

\title{
Wasp Parasitoid, Diadegma insulare (Cresson) (Insecta" Hymenotera: Idhneumonidae) ${ }^{1}$
}

\section{Andrei Sourakov and Everett Mitchell ${ }^{2}$ \\ Distribution}

Diadegma insulare is found in the United States and South America: New Hampshire west to southern British Columbia, south to Florida, Texas and California; Hawaii, West Indies and Mexico south to Venezuela.

These wasps are found in cruciferous crops, overwintering as a cocoon. The number of generations per year corresponds to the number of generations of its hosts: Hellula undalis (F.), Plutella armoracia Bsk., and P. xylostella (L.), the diamondback moth.

\section{Description}

\section{Egg}

The egg is clear, and is hard to distinguish from the host's fat body when it is dissected. Unlike Cotesia plutella, another parasitoid of the diamondback moth, the egg is rounded rather than pointed and lacks a projection.

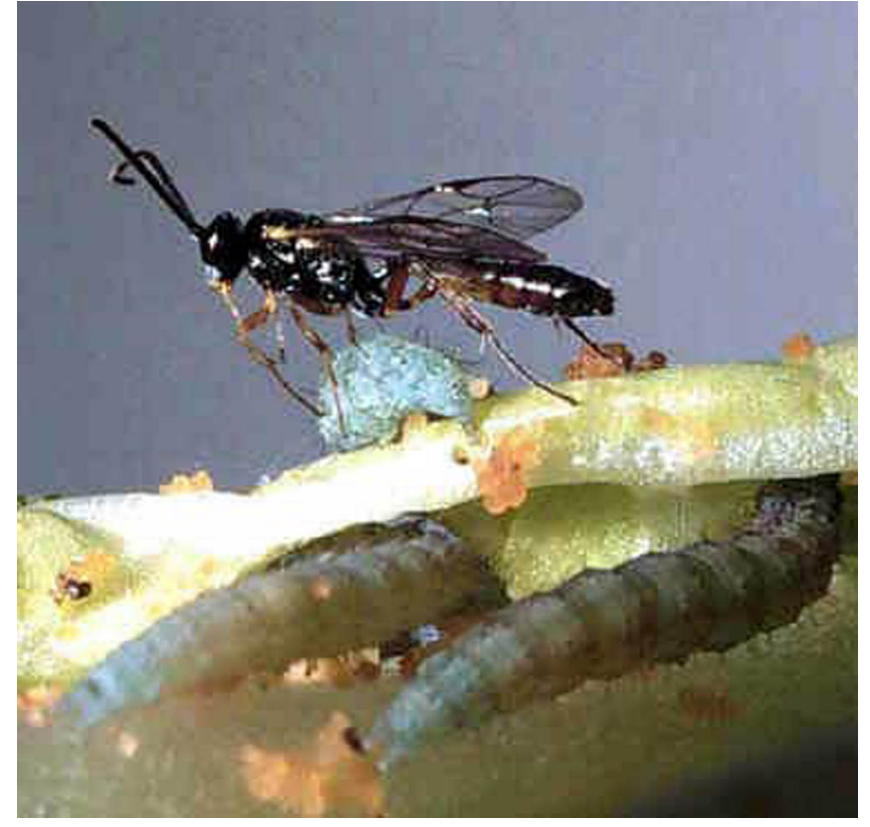

Figure 1. Male Diadegma insulare (Cresson), a parasitoid wasp, and mature larvae of the diamondback moth, Plutella xylostella (Linnaeus). Credits: Andrei Sourakov, USDA

\section{Larva}

The larva of $D$. insulare is white and can be noticed more easily in a dissected host due to its extensive movements. It looks strongly segmented

\footnotetext{
1. This document is EENY-124 one of a series of Featured Creatures from the Entomology and Nematology Department, Florida Cooperative Extension Service, Institute of Food and Agricultural Sciences, University of Florida. Published: March 2000. This document is also available on Featured Creatures Website at http://creatures.ifas.ufl.edu. Please visit the EDIS Website at http://edis.ifas.ufl.edu. Additional information on these organisms, including many color photographs, is available at the Entomology and Nematology Department website at http://entnemdept.ifas.ufl.edu/.

2. Andrei Sourakov and Everett Mitchell, USDA, Gainesville, FL.
} 


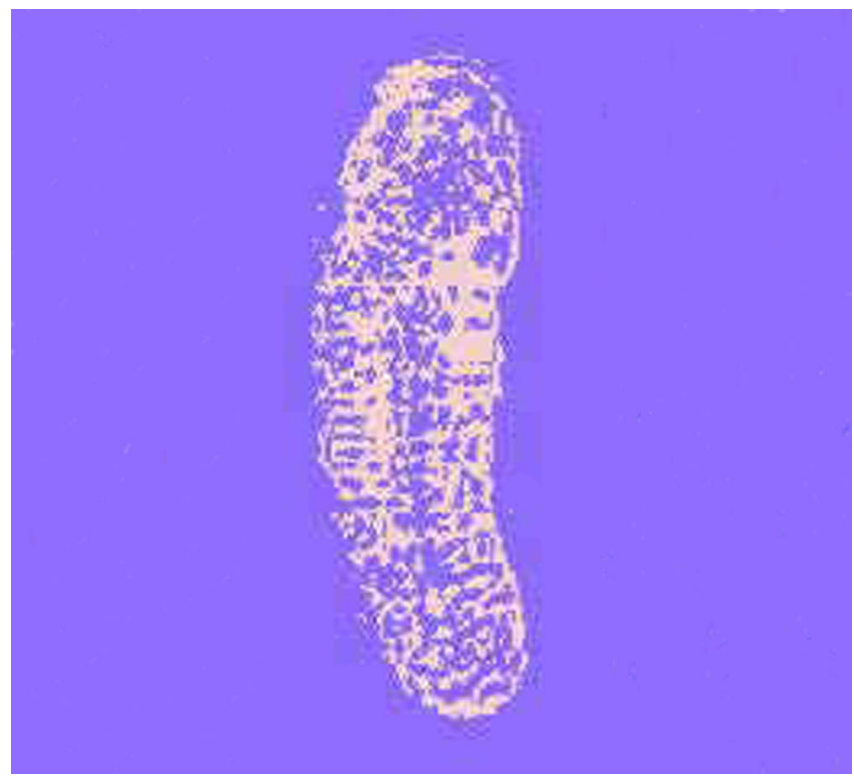

Figure 2. Egg of Diadegma insulare (Cresson), a parasitoid wasp. Credits: Guangye Hu , USDA

and bears a short ( $1 / 4$ of the total length of the larva) narrow "tail".

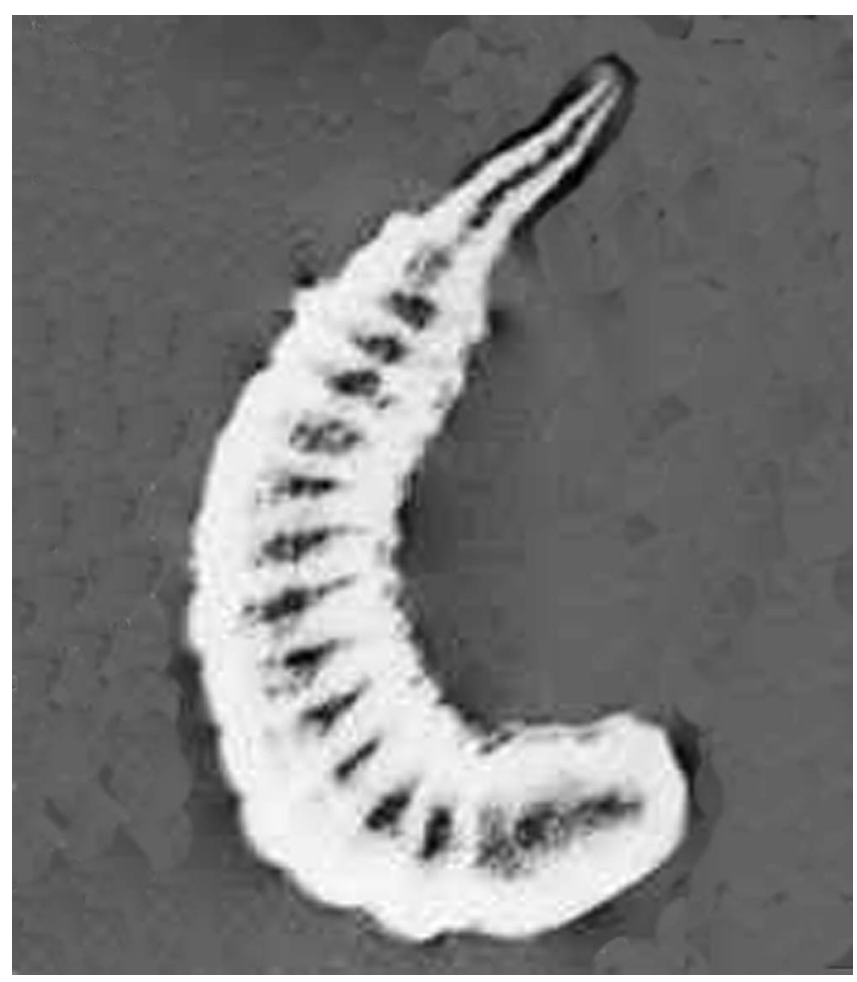

Figure 3. Mature larva of Diadegma insulare (Cresson), a parasitoid wasp. Credits: Guangye Hu , USDA

\section{Pupa}

The larva of $D$. insulare stays inside the diamondback moth larva until the latter spins a cocoon and is ready to pupate. Once emerged, $D$. insulare's larva spins its own cocoon inside the cocoon of the moth.

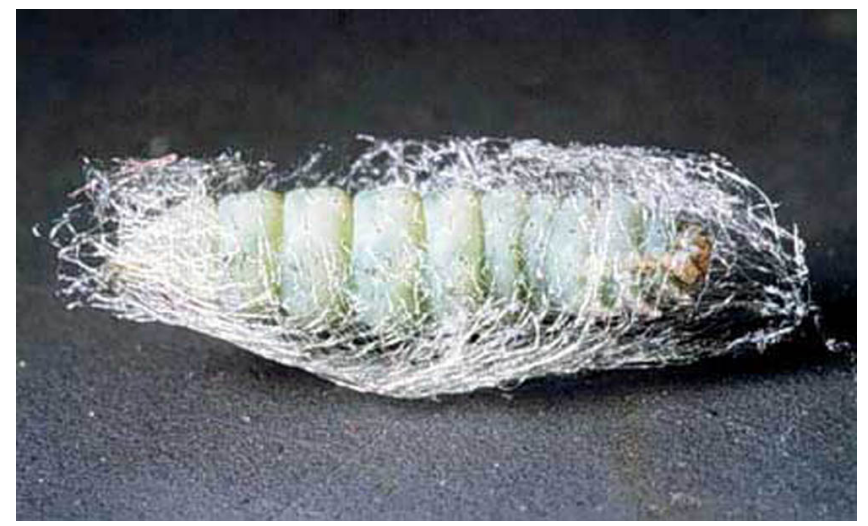

Figure 4. Pre-pupa of diamondback moth, Plutella xylostella (Linnaeus), inside the cocoon. Credits: Andrei Sourakov, USDA

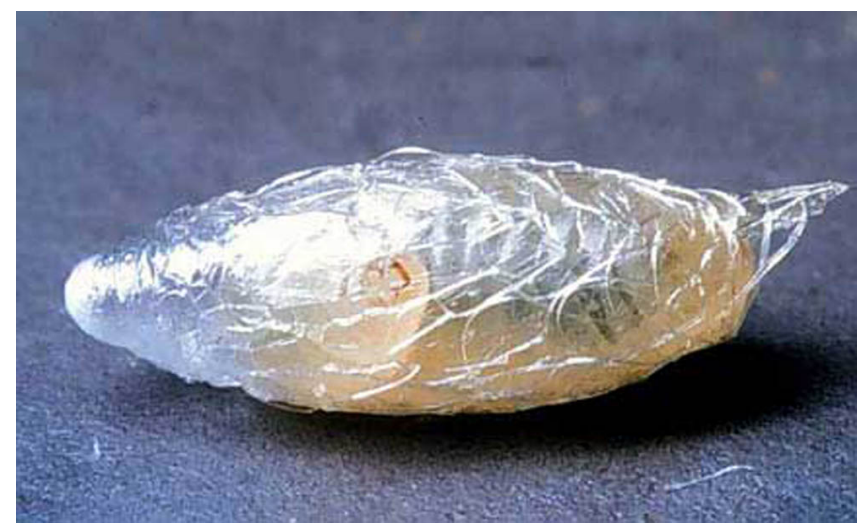

Figure 5. Larva of Diadegma insulare (Cresson), a parasitoid wasp, spinning its cocoon inside the cocoon of a diamondback moth. Credits: Andrei Sourakov, USDA

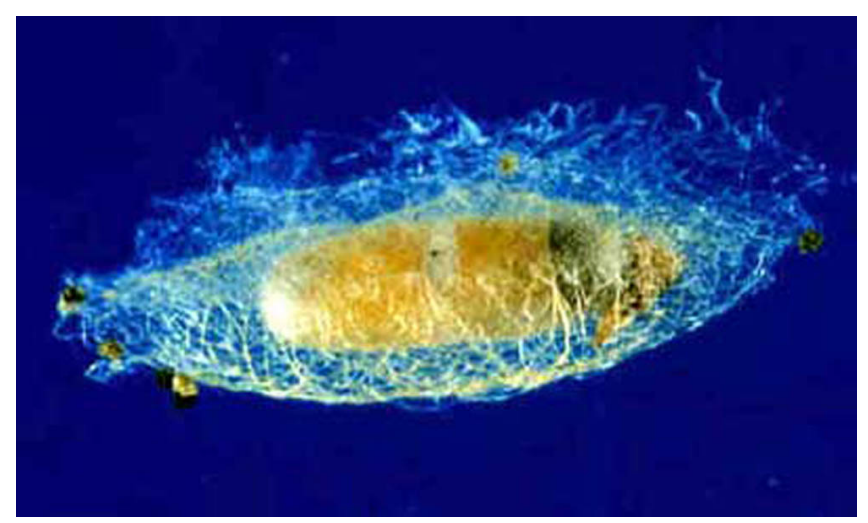

Figure 6. Cocoon of Diadegma insulare (Cresson), a parasitoid wasp. Credits: Guangye Hu , USDA

\section{Adult}

The length of this wasp does not exceed $6 \mathrm{~mm}$. The female has a well defined ovipositor. 


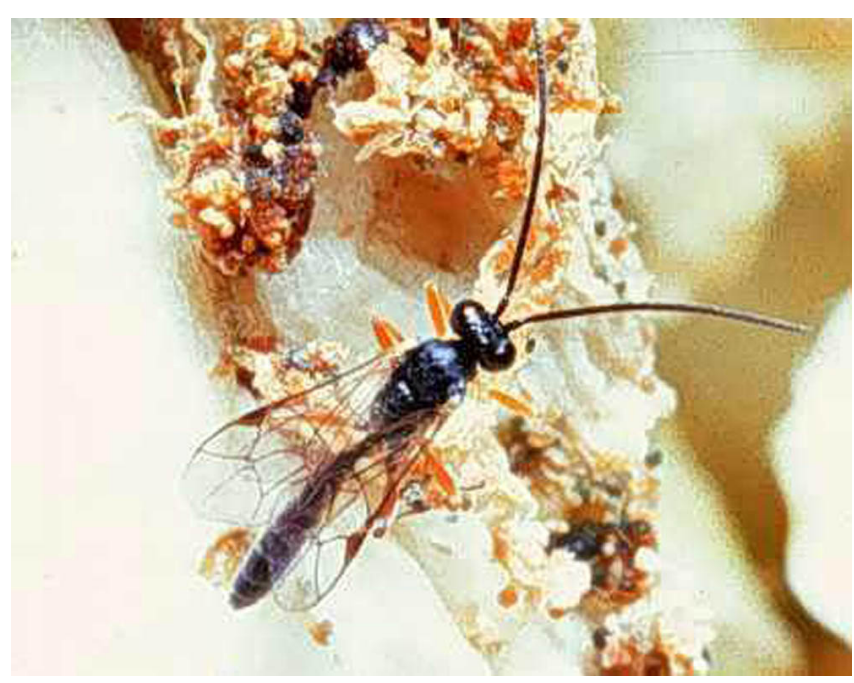

Figure 7. Male Diadegma insulare (Cresson), a parasitoid wasp. Credits: Andrei Sourakov, USDA

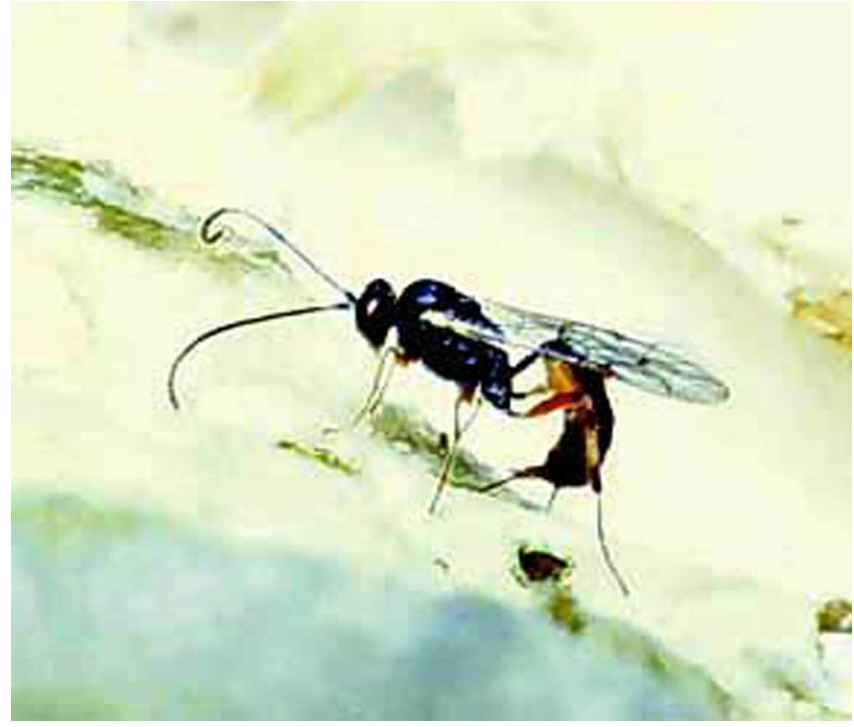

Figure 8. Female Diadegma insulare (Cresson), a parasitoid wasp, laying an egg into a larva of the diamondback moth through the hole in a cabbage leaf. Credits: Andrei Sourakov, USDA

\section{Importance}

D. insulare is the most important naturally occurring enemy of the diamondback moth as it can parasitize up to $90 \%$ of its larvae. Not only the parasitized larvae die, but they also do less damage, consuming $80 \%$ less food than the non-parasitized individuals. $D$. insulare can be reared in captivity, but mass rearing presents many challenges. For instance, the wasps rarely parasitize larvae that are reared on artificial diet. Hence, the larvae have to be presented to the wasps while feeding on a cruciferous plant (e. g., cabbage).

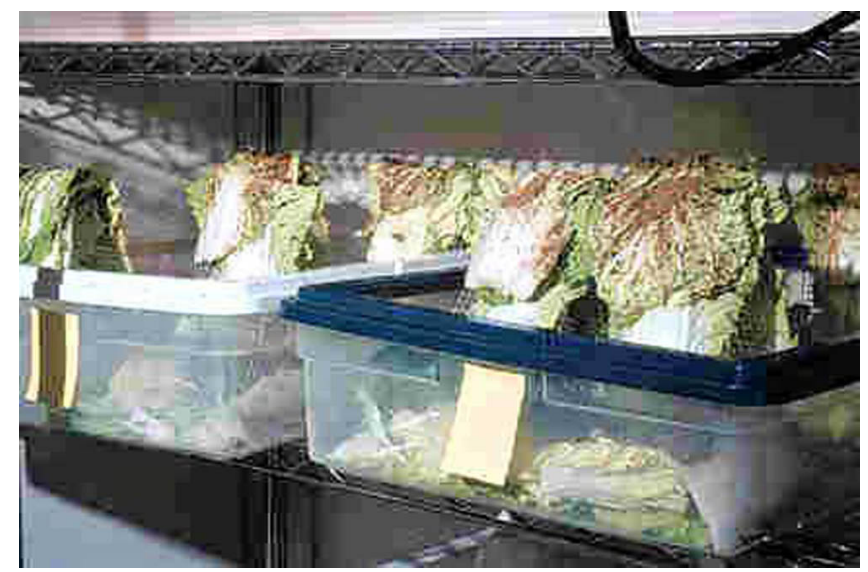

Figure 9. Rearing containers for Diadegma insulare (Cresson), a parasitoid wasp. Inside a walk-in rearing chamber, the leaves of collards infested with diamondback moth larvae are presented to the free-flying wasps. Credits: Andrei Sourakov, USDA

\section{Conservation}

D. insulare is highly susceptible to pesticides, which kill adult wasps through direct contact. The larvae inside the host also die when pesticides kill their hosts. Thus, major outbreaks of the diamondback moth are more likely in fields that are sprayed heavily, and to avoid such outbreaks one needs to conserve the Diadegma populations by planting its nectar sources and limiting the use of pesticides.

\section{Selecterd References}

Harcourt, D.G. 1960. Biology of the Diamondback Moth, Plutella maculipennis (Curt.) (Lepidoptera: Plutellidae), in Eastern Ontario. III. Natural Enemies. The Canadian Entomologist, 92: 419-428.

Harcourt, D.G. 1963. Major mortality factors in population dynamics of the diamondback moth, Pluttella maculipennis (Cur.) (Lepidoptera: Plutellidae). Mem. Canadian Entomol. Soc. 32: 55-56.

Hoffmann, M.P. and Frodsham, A.C. 1993. Natural Enemies of Vegetable Insect Pests. Cooperative Extension, Cornell University, Ithaca, NY. 63 pp.

Idris, A. B. and E. Grafius. 1993. Field studies on the impact of pesticides on the diamondback moth, 
Plutella xylostella (L. ) (Lepidoptera: Plutellidae) and parasitism by Diadegma insulare (Cresson) (Hymenoptera: Ichneumonidae). J. Econ. Entomol. 86: 1196-1220.

Lasota, J. A., Kok L. T. 1986. Diadegma insulare (Hymenoptera: Ichneumonidae) parasitism of the diamondback moth (Lepidoptera: Plutellidae) in southwest Virginia. J. Entomol. Sci. 21: 237-242.

Mitchell, E. R., G. Y. Hu, and J. S. Okine. 1997. Diamondback moth (Lepidoptera: Plutellidae) infestation and parasitism by Diadegma insulare (Hymenoptera: Ichneumonidae) in collards and adjacent fields. Florida Entomol. 80: 54-62.

Mitchell, E. R. et al. (February 2000). Stage by stage comparison of parasitoids important in biocontrol of cabbage pests. USDA. http://www.usda.ufl.edu/biocontrol/guide.htm (March 2000). 